\title{
Trabalho Docente e as Influências de Forças Coercitivas: um Estudo em uma Universidade Privada
}

\section{Teaching Work and the Influences of Coercive Forces: a Study in a Private University}

\author{
Carla Façanha \\ Universidade de Fortaleza - UNIFOR - Brasil \\ carlamariaholanda@gmail.com \\ ORCID: 0000-0003-1443-9893 \\ Mônica Tassigny \\ Universidade de Fortaleza - UNIFOR - Brasil \\ monica.tass@gmail.com \\ ORCID: 0000-0001-9483-0547 \\ Marcos Lima \\ Universidade de Fortaleza - UNIFOR - Brasil \\ marcos.a.lima@terra.com.br \\ ORCID: 0000-0001-5541-6220 \\ Fabiana Bizarria \\ Universidade de Fortaleza - UNIFOR - Brasil \\ bianapsq@hotmail.com \\ ORCID: 0000-0001-8365-8593
}

Submetido em 13/11/2017; Aprovado em 30/09/2018

\section{Resumo}

O ambiente educacional superior tem enfrentado inúmeras mudanças, que marcam várias transformações no âmbito do ensino e da aprendizagem, exigindo assim, principalmente dos docentes, novos posicionamentos em frente às influências das forças coercitivas relacionadas aos órgãos reguladores (Ministério da Educação - MEC), mercado e cliente. Este estudo teve, como objetivo geral, identificar e descrever como as forças coercitivas exercem influência sobre o trabalho. 0 estudo foi desenvolvido a partir de uma pesquisa qualitativa e os dados foram coletados por meio de duas técnicas: grupo focal e entrevista. Dentre os estudos na área, este faz-se original por associar a temática "trabalho docente e teoria institucional" e também pela escolha de duas técnicas e dois públicos distintos, possibilitando um maior aprofundamento, dentro de duas visões distintas do fenômeno das influências das forças coercitivas sobre o trabalho docente. Os resultados evidenciaram percepções distintas entre os grupos de professores e os de coordenadores, com relação às influências das forças coercitivas: dos órgãos reguladores, do mercado e do cliente; sobre o trabalho docente. Desse modo, evidenciou-se que os docentes apresentaram percepções mais negativas em relação às forças coercitivas, enquanto os coordenadores consideraram mais positivas, na medida em que as reconheceram como meio de regulamentação e alinhamento do ambiente institucional de educação superior, reforçando assim o entendimento da teoria institucional com o conceito isomórfico.

Palavras-chave: Trabalho Docente. Forças Coercitivas. Teoria Institutional.

\begin{abstract}
The higher educational environment has faced many changes, which mark several transformations in the scope of teaching and learning, thus requiring, especially of teachers, new positions against the influences of coercive forces related to the regulatory bodies (Ministry of Education - MEC), market and customer. This study aimed to identify and describe how coercive forces influence work. The study was developed from a qualitative research and the data were collected through two techniques: focus group and interview. Among the studies in the field, this one is original because it associates the theme "teaching work and institutional theory" and also by the choice of two techniques and two distinct
\end{abstract}


publics, allowing a greater deepening, within two distinct visions of the phenomenon of the influences of the forces on teacher work. The results showed different perceptions between the teacher and coordinator groups regarding the influence of the coercive forces: of regulatory bodies, market and the customer; on teaching work. Thus, it was shown that teachers presented more negative perceptions regarding coercive forces, whereas the coordinators considered them more positive, since they recognized them as a means of regulation and alignment of the institutional environment of higher education, thus reinforcing the understanding of the institutional theory with the isomorphic concept. Keywords: Teaching Work. Coercive forces. Institutional Theory.

\section{Introdução}

O campo de investigação do trabalho docente vem crescendo desde a última década (2000), em função das mudanças no contexto social, que refletem diretamente nas Instituições de Ensino Superior [IES] e devido ao aumento significativo da oferta de cursos de graduação e pós-graduação no Brasil (Silva \& Mafra, 2014). Essa expansão do Ensino Superior se concentra principalmente nas instituições privadas, que tiveram um crescimento da ordem de $347,15 \%$, enquanto na rede pública o aumento foi de apenas 134,58\% entre o período de 1995 e 2010 (INEP,2011).

0 aumento de instituições de Ensino Superior tem-se refletido no aquecimento da educação superior e, consequentemente, gerando novos posicionamentos dos docentes, em frente aos desafios presentes nas condições de trabalho e nas tendências de mercado. Descrever como essas influências são percebidas pelos docentes, sob a ótica da teoria institucional, mostra-se relevante, pois apesar de existirem estudos dessa teoria focando-se no entendimento dos fenômenos das IES, não estão relacionadas as influências direta das forças dos órgãos reguladores, mercado e cliente sobre o trabalho docente (Alperstedt, Martignago \& Fiates, 2006; Ferro \& Gonçalves, 2010). Inúmeras são as influências que emergem no ambiente das IES e que exercem pressões diretas no trabalho do docente, a teoria institucional pode ser utilizada como recurso para entender o funcionamento dessas influências que se configuram como forças coercitivas. Assim, a teoria institucional visa entender como as organizações se adaptam a sua estrutura e cultura organizacional, para enfrentar valores socialmente estabelecidos pelos ambientes externo e interno, tendo seu foco voltado para a institucionalização dos controles normativos como padrões de crenças, valores e normas (Carvalho, Vieira \& Lopes, 1999; Di Maggio \& Powell, 1991; Meyer \& Rowan, 1991).

Diante desse "gap" teórico sobre a relação entre trabalho docente e teoria institucional, a pesquisa visa a responder o seguinte questionamento: Como as forças coercitivas exercem influências no trabalho docente em IES privada? 0 diferencial do estudo está em estabelecer a relação entre teoria institucional e trabalho docente, a partir dos aspectos coercitivos, que se configuram como pressões internas e externas ao ambiente institucional, a fim de ocasionar a uniformização nas organizações e ambiente institucional de ensino superior. Diante disso, a pesquisa tem como objetivo identificar e descrever como as forças coercitivas exercem influência sobre o trabalho docente. No estudo, foram analisadas as pressões vindas não só dos órgãos reguladores, mas do mercado e do cliente, sob o trabalho do docente, por meio das percepções dos docentes e coordenadores de cursos ocasionando a necessidade de uniformização das instituições.

\section{Docente universitário e campo institucional e suas forças coercitivas}

0 docente universitário encontra-se inserido em um ambiente em constante processo de turbulência ambiental. A busca crescente de respostas para os processos de interação e adaptação entre as organizações universitárias e o ambiente externo, tem se tornado um fenômeno fundamental para a sobrevivência dessas organizações, exercendo influência na instituição e diretamente entre os docentes (Alperstedt, Martignago \& Fiates, 2006).

A teoria institucional define, como base, que a influência sobre as organizações é executada por diversos grupos ou normas sociais, tanto dentro do ambiente, como externo ao ambiente das organizações. Dessa forma, pode ser compreendido que o docente sofre influência dos padrões institucionalizados no ambiente institucional, que são influenciados por mecanismos coercitivos (Dimaggio \& Powell, 1991).

A inserção do docente no trabalho leva em consideração a heterogeneidade das condições do ambiente entre o público e o privado, mas apesar dessa separação entre as instituições, os dois ambientes partilham características semelhantes, o que diferem os contextos institucionais. Segundo os 
estudos de Balbachevsky (2007), são duas variáveis: (1) proporção de doutores, que revela ser um indicador importante para sedimentar as atividades de pesquisa dentro das instituições; e (2) a proporção de professores da instituição com vínculo integral ou dedicação exclusiva.

O ensino superior no Brasil é regulado pelo governo federal, por meio do MEC e de outros órgãos associados pelo Ministério da Educação [MEC], como Conselho Nacional de Desenvolvimento Científico e Tecnológico [CNPQ] e Coordenação de Aperfeiçoamento de Pessoal do Nível Superior [CAPES]. Apesar do controle desses órgãos, o estado não possui monopólio, pois o ensino superior é também oferecido pelo setor privado. (Barreyro \& Rothen, 2007; Scaglione \& Costa, 2011). Com esse crescimento, observase que o governo reduz a responsabilidade em ofertar ensino superior e transfere esse papel ao setor privado, promovendo um elevado índice de expansão do número de oportunidades de cursos, ocorrendo um aquecimento deste serviço no Brasil (Ferro \& Gonçalves, 2007). Dentro desse cenário, as instituições e os docentes sofrem pressões dos órgãos legais como também do mercado, sob duas óticas relacionadas tanto a demanda por receber profissionais qualificados quanto sob o aspecto do mercado educacional na qual se configura cada vez mais competitivo e dos alunos dentro do conceito de cliente exigindo sempre a disponibilização dos melhores serviços.

A teoria institucional, nos últimos anos, recebeu algumas mudanças que têm tido reflexo no seu renascimento no campo das ciências sociais. Para alguns teóricos, essas mudanças são vistas como uma orientação teórica e não como uma construção de uma nova teoria (Dimaggio \& Powell, 1991). Dessa forma, várias organizações sociais são moldadas dentro de uma complexa estrutura que exerce pressão para a formação de um isomorfismo institucional (Hasselbladh \& Kallinikos, 2000).

Portanto, o isomorfismo institucional define como as organizações se estruturam e reflete uma sociedade socialmente construída a partir das exigências do seu ambiente, tornando-as homogêneas, sem necessariamente as tornarem mais eficientes (Di Maggio \& Powell, 1991; Meyser \& Rowan, 1991). As forças isomórficas, conforme definido por Di Maggio e Powell (1991), são as seguintes: (1) isomorfismo coercitivo, que remete às forças resultantes das pressões de outras organizações, órgãos e expectativas da sociedade, exercidas nas organizações, tanto formais como informais; (2) isomorfismo mimético que reflete às incertezas e que fortalece a imitação; e (3) isomorfismo normativo, que se associa ao domínio das profissões. Essas pressões, comuns nas três forças, proporcionam a homogeneidade das organizações e o processo de mudança surge a partir das imposições no campo institucional.

Quando se especifica o estudo para entendimento do campo institucional das universidades como fator coercitivo, pode-se destacar que as IES brasileiras sofreram ao longo dos anos reformas educacionais que exerceram influência em sua dinâmica de estruturação e sobrevivência (Carvalho, Vieira \& Silva 2012). Nos últimos anos, em virtude da globalização, as instituições estão vivendo um momento de transição, no que se refere ao modo de gestão, deixando de lado uma administração burocrática e passando a ter uma gestão mais empresarial (Maués, 2009). Os alunos se tornam clientes, e os cursos, produtos. Com esse novo posicionamento, o professor passa a ser um mero prestador de serviços, tirando do foco o papel de educador. A lógica do ensino-aprendizagem é subvertida pela lógica do consumo-satisfação e destitui o objetivo da formação de um sujeito maduro e reflexivo (Alcadipani, 2011).

Analisando a influência das forças coercitivas dos órgãos reguladores, o governo estabelece por intermédio do MEC maior participação nas políticas de educação superior, determinando diversos projetos de reforma constitucional e leis que criam mudanças, principalmente no sistema de avaliação, de financiamento e na relação mais próxima da universidade como o mercado. Assim, é percebido um direcionamento para a formação profissional, flexibilidade, competitividade e avaliação, por meio de uma diversidade de estabelecimentos, que surgem visando obedecer às demandas do mercado (Ferro \& Gonçalves, 2007).

Dessa forma, há uma produção tecnológica e científica que apresenta vantagens para dar apoio ao processo de concorrência, garantindo a legitimação do próprio sistema educacional. Assim, o professor universitário precisa atuar num complexo sistema que engloba diferentes tipos de pressões institucionais. As determinações da Lei de Diretrizes e Bases da Educação Nacional (LDB/1996) estabelece atividades de ensino, pesquisa e extensão e lança além das obrigações institucionais burocráticas, pressões voltadas para exigências de órgãos regulamentadores, como a CAPES, e o sistema Qualis/CAPES de citação e a atualização do Currículo Lattes. O docente está, cada vez mais, em situação de isolamento, afastando-o de qualquer relação que não seja a de produção. Essas pressões, que se pode 
configurar como forças coercitivas, configuram um trabalho docente desprivilegiado e preconizado (Silva \& Mafra, 2014). 0 Capes, em sua estratégia de avaliação, privilegia a quantidade de publicações, gerando consequências em relação a qualidade da produção científica, como também na manutenção da formação didático - pedagógico do docente que atua na graduação (Vosgerau, Orlando \& Meyer, 2017).

Quando se avalia as influências do mercado, este assume aspectos importantes que refletem diretamente na postura do docente em sala de aula. A sociedade se encontra na busca por mudanças, que são necessárias para transformar as IES em escolas, com referência na formação ampla, na qual esteja envolvido a formação ética e cidadã do indivíduo (Guimarães \& Lima, 2016). 0 que se percebe é uma dissociação entre a missão das IES e à sociedade. 0 que se espera é um ensino-aprendizagem de uma maneira mais participativa e atenta às mudanças ambientais, na qual possa agregar no ambiente social, independente do âmbito profissional. Além do mercado de trabalho consumidor, as IES estão também tendo que enfrentar o mercado de concorrência entre as IES. (Rowe, Bastos \& Pinho, 2011).

Outro aspecto de influência refere-se ao cliente que deve ser ressaltado no sistema educacional superior, na qual envolve 2 (duas) importantes mudanças que merecem destaque. A primeira é quanto ao processo de massificação de acesso ou democratização do acesso, ocasionando maior diversidade do corpo discente. A diversidade cultural, que antes não era acentuada, passa a ser um desafio para os docentes, pois eles precisam saber lidar com esse novo aluno que surge de um segmento social que até há pouco não era "sujeito" deste nível de educação. Os discentes que chegam, muitas vezes, se encontram pouco motivados e comprometidos com sua aprendizagem e, por outro lado, é um público exigente quanto à qualidade do curso, em virtude do alto grau de competitividade de mercado de trabalho (Pachane \& Pereira, 2004; Setton, 2005; Zago, 2006). O novo aluno universitário, possuem uma escolaridade média insuficiente, com pouco contato com outras formas de objetos intelectuais e artísticos da cultura hegemônica. Além disso, costumam ter pouca disponibilidade para estudar diurnamente e para participar do ambiente acadêmico, pois trabalham durante o dia. Todos esses aspectos interferem diretamente nas práticas intelectuais e nas avaliações internas das IES (Bourdieu, 2011).

Por outro lado, ao mesmo tempo, esse novo aluno encontra-se inserido dentro de uma era digital e apresenta-se curioso e com grande habilidade em utilizar recursos tecnológicos para as mais diversas finalidades (entretenimento, informação, aprendizagem, comunicação, consumo, construção de personalidade e de identidade social, consolidação de redes de sociabilidade (Freire \& Lemos, 2008). Diante desse cenário, o professor precisa entender e analisar essa realidade que emerge e procura desenvolver estratégias que o permitam pensar sobre o seu papel como docente dentro um contexto mais amplo.

\section{Metodologia}

Esta pesquisa realizada em 2016 foi registrada na Plataforma Brasil por meio do envolvimento do Comitê de Ética de Pesquisa [CEP] e da Comissão Nacional de Ética em Pesquisa de Universidade [CONCEP], tendo a aprovação do colegiado, sob o parecer n. 1706.456, em atenção à Resolução CNS/MS $466 / 12$ e diretrizes

A pesquisa caracteriza-se como abordagem qualitativa explicativa, tendo como base Godoy (2005), pois o estudo visa identificar e descrever como as forças coercitivas exercem influência sobre o trabalho docente. Por meio desse objetivo, entender como as forças coercitivas, presentes nos órgãos reguladores, mercado e cliente influenciam o trabalho docente universitário, torna-se o ponto central da pesquisa. Para o alcance do objetivo, a pesquisa foi composta por duas técnicas de coleta de dados: grupo focal e entrevista semiestruturada.

A escolha do grupo focal possibilitou a exploração das atitudes e das necessidades do grupo, por via da percepção de diferentes formas de comunicação, utilizadas pelos participantes no dia a dia. Além disso, explorou diversas perspectivas, identificando valores e crenças comuns ou divergentes, dentro da discussão em grupo (Silva, Silva \& Mesquita, 2014).

A instituição escolhida para a coleta de dados foi uma instituição de ensino superior privada de Fortaleza-CE. A escolha da instituição ocorreu de forma intencional, por ser a primeira instituição universitária privada do estado do Ceará, que além da maturidade acadêmica, tem grandes vivências sobre as diversas influências de forças coercitivas no decorrer de sua trajetória de existência.

0 centro de estudo priorizado neste estudo foi do centro de Ciências da Comunicação e Gestão [CCG] por ser o centro com maior diversidade de cursos dentro da instituição (administração, 
audiovisual, comércio exterior, ciências contábeis, ciências econômicas, jornalismo, publicidade e propaganda). Com essa diversidade, foi possível levantar as diversas percepções sobre como as forças coercitivas exercem influência no trabalho do docente. A triagem dos participantes foi feita de forma intencional, pois foram selecionados 28 professores de forma aleatória, que se encontravam entre os cursos de turismo, economia, administração, publicidade e jornalismo. Além da diversidade de cursos, outro aspecto priorizado na seleção foi a diversidade do perfil dos participantes, relacionando as características de titulação (especialista, mestre, doutor e pós-doutor), categoria de trabalho (auxiliar, assistente, adjunto, associado e titular) e regime de trabalho (horista, parcial e integral), tendo em comum, o campo de atuação na graduação. Dos 28 participantes convidados por meio de e-mail formal, enviado pela instituição e contato telefônico feito pela secretaria do centro, foram confirmados 10 participantes que, para a aplicação da técnica do grupo focal, se torna aceitável (Fraser \& Gondim, 2004).

A estruturação da dinâmica do grupo focal foi fundamentada nos seguintes teóricos: Barbour (2009) e Bauer e Gaskell (2002). Sua aplicação considerou as seguintes etapas: (i) esclarecimento antes das discussões em grupo, os participantes foram notificados e assinaram o termo de consentimento, com esclarecimento sobre a condução da técnica e sobre a importância da participação com a confiabilidade dos dados; e (ii) iniciação - no momento de iniciação da técnica, o pesquisador esclareceu a temática do estudo e apresentou os aspectos coercitivos, especificando os aspectos dos órgãos reguladores, mercado e cliente como fatores que influenciam os próprios docentes. As discussões seguiram as questões especificadas no quadro 1, que foi elaborado a partir dos objetivos da pesquisa, tendo como fundamentação teórica os autores da teoria institucional.

\begin{tabular}{|c|c|c|c|}
\hline FundamentaçãoTeórica & Tema & $\begin{array}{l}\text { Pontos Importantes do } \\
\text { objetivo da pesquisa }\end{array}$ & Perguntas - Grupo Focal \\
\hline \multirow{3}{*}{$\begin{array}{c}\text { Alperstedt, } \\
\text { Martignago \& Fiates } \\
\text { (2006) } \\
\text { Dimaggio; \& Powell } \\
\text { (1991) } \\
\text { * Alcadipani (2011) }\end{array}$} & \multirow{3}{*}{$\begin{array}{l}\text { Fatores } \\
\text { Coercitivos } \\
\text { isomórficos } \\
\text { institucional }\end{array}$} & $\begin{array}{l}\begin{array}{l}\text { Analisar como as } \\
\text { coercitivas forças } \\
\text { reguladores }\end{array} \\
\end{array}$ & $\begin{array}{l}\text { * Como os orgãos reguladores exercem } \\
\text { influencias no trabalho do docente? }\end{array}$ \\
\hline & & $\begin{array}{l}\text { Analisar as forças coercitivas } \\
\text { (Mercado) }\end{array}$ & $\begin{array}{l}\text { * Quais são as pressões e Influências } \\
\text { exercida pelo mercado no trabalho do } \\
\text { docente? }\end{array}$ \\
\hline & & $\begin{array}{l}\text { Analisar as forças coercitivas } \\
\text { (Cliente) }\end{array}$ & $\begin{array}{l}\text { * Quais são as pressões e Influências } \\
\text { exercida pelo Cliente no trabalho do } \\
\text { docente? }\end{array}$ \\
\hline
\end{tabular}

Quadro 1. Guia com fundamentos teóricos para a discussão do grupo focal

Fonte: Elaborada pelos autores (2018).

No final da técnica, que corresponde a etapa (III) Fechamento, o pesquisador agradeceu aos participantes, realizando um fechamento dos principais pontos discutidos e solicitando em seguida que eles preenchessem o formulário de caracterização.

Com objetivo de ampliar o entendimento sobre como essas forças coercitivas exercem influência sobre o trabalho do docente, foi realizado também, agora sob a ótica de 4 (quatro) coordenadores dos cursos do CCG, entrevista por meio de um roteiro de questões semiestruturadas, similar às questões abordadas no grupo focal, abordando questões abertas, focando o entendimento sobre como as forças exercem influência no trabalho, e quais os principais desafios enfrentados pelos docentes frente às influências. A escolha desse método, para complementar o estudo, possibilitou maior compreensão dos significados, dos valores e das opiniões dos atores envolvidos na situação coercitiva, vivenciada no ambiente institucional (Fraser \& Gondim, 2004).

Os participantes dessa etapa de coleta de dados, foram informados que durante o processo de entrevista, seria utilizado instrumento para gravação do áudio. A seleção dos entrevistados foi feita de forma intencional, pois foram priorizados os coordenadores dos cursos do CCG, que participaram do grupo focal, visando ampliar a percepção sobre o tema, a partir de uma visão ampliada da gestão de coordenadores.

Para tratamento dos dados, foram adotados na pesquisa o método de análise de conteúdo que, segundo Bardin (2012), visa a descobrir os pontos de sentido presentes na composição da comunicação e a frequência do surgimento, as quais podem representar algum sentido para o objetivo do estudo.

Na realização da análise de conteúdo, foram seguidas 4 (quatro) etapas para a organização da 
análise: pré-análise, exploração do material, tratamento dos resultados obtidos e interpretação. As categorias foram preestabelecidas com o objetivo de direcionar o início do estudo, mas as unidades de registro emergiram durante a coleta dos dados e sofreram alterações durante o momento de codificação de acordo com o quadro 2 (Minayo, 2007).

\begin{tabular}{|c|c|c|}
\hline \multirow{2}{*}{ CATEGORIAS } & $\begin{array}{c}\text { UNIDADE DE REGISTRO } \\
\text { DOCENTES - GRUPO FOCAL }\end{array}$ & $\begin{array}{c}\text { UNIDADE DE REGISTRO } \\
\text { COORDENADORES - ENTREVISTAS }\end{array}$ \\
\hline \multirow{2}{*}{$\begin{array}{c}\text { Forças coercitivas } \\
\text { dos orgãos } \\
\text { reguladores }\end{array}$} & \multicolumn{2}{|c|}{ Dimensão ensinar e pesquisar/ Produção Cientifica } \\
\cline { 2 - 3 } & $\begin{array}{c}\text { Conflito academicismo e } \\
\text { mercadológico }\end{array}$ & Promoção de linearidade da matriz, corpo docente e discente \\
\cline { 2 - 3 } & Incentivo governamental & Influências de outros órgãos reguladores \\
\hline $\begin{array}{c}\text { Forças coercitivas } \\
\text { do mercado }\end{array}$ & \multicolumn{2}{|c|}{ Relação com o mercado concorrente } \\
\cline { 2 - 3 } $\begin{array}{c}\text { Forças coercitivas } \\
\text { do cliente }\end{array}$ & \multicolumn{2}{|c|}{ Perfil esperado = Teoria + prática } \\
\cline { 2 - 3 } & \multicolumn{2}{|c|}{ Termômetro para o processo de ensino e aprendizagem } \\
\hline
\end{tabular}

Quadro 2. Categorias e unidade de registro de análise

Fonte: Elaborada pelos autores (2018).

Em seguida, os dados foram transcritos, tendo o grupo focal registrado 1 hora e 36 minutos de áudio e imagem e as 4 entrevistas totalizando 3 horas e 21 minutos. Por fim, foi feita codificação dos trechos para facilitar o processo de tratamento eletrônico utilizado no software Atlas/TI. Os relatos inseridos na análise dos resultados foram codificados da seguinte forma: D - Docentes (Grupo Focal) e C - Coordenadores (Entrevista). E as figuras gráficas, extraídas por meio do software, tiveram o objetivo de explicitar as relações entre as forças, por meio das setas, com as unidades de registro que emergiram da fala dos participantes da pesquisa, fazendo com que as categorias que foram pré-estabelecidas atendessem aos objetivos do estudo.

\section{Discussões de resultados}

A primeira força coercitiva referente aos órgãos reguladores que corresponde as pressões oriundas do MEC, como principal órgão legal, mas também foram identificados outros órgãos que se encontram inseridos naquele ministério como: Capes e CNPq e também os conselhos regionais dos cursos, foi percebido que entre as forças estudadas, essa apresentou uma maior diferenciação de percepções e de entendimento sobre como os órgãos reguladores exercem influência no trabalho docente.

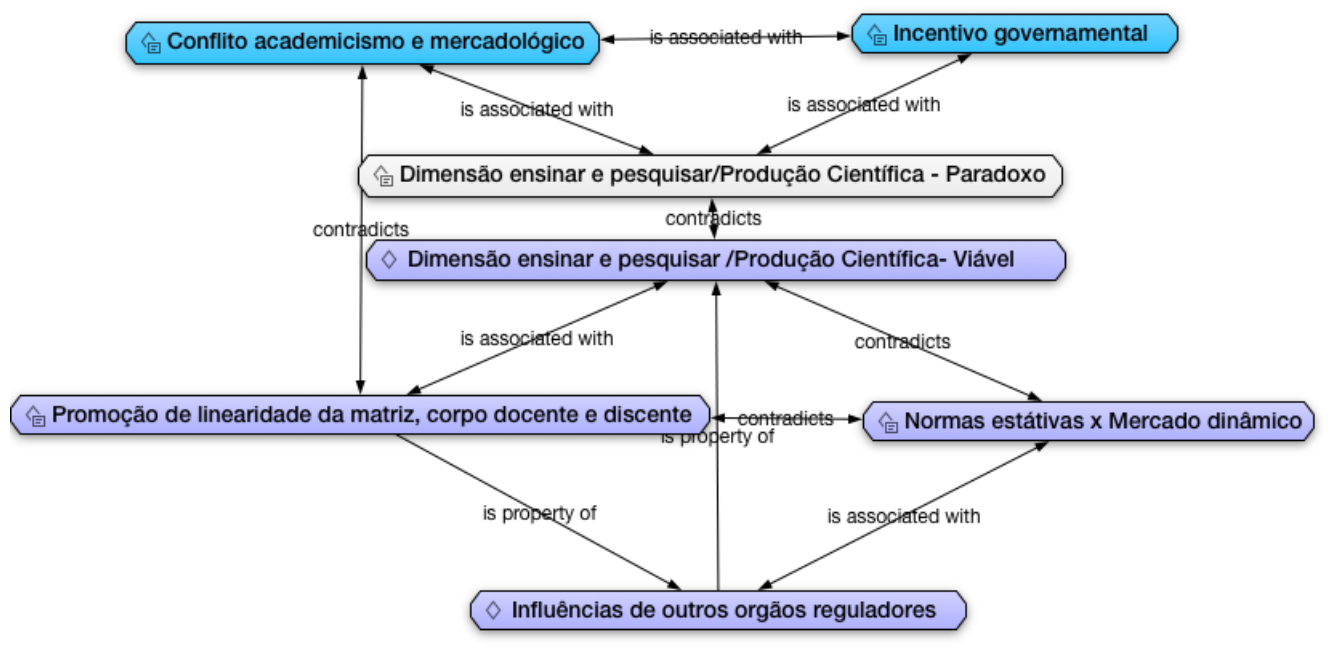

Figura 1. Resultados analisados no Atlas/TI: coleta de dados do Grupo Focal e Entrevistas - categorias órgãos reguladores

Fonte: Elaborada pelos autores com base nos dados da pesquisa (2016).

No grupo de docentes, foi identificado que as influências dos órgãos reguladores geram conflito entre os mundos acadêmico e o mercadológico. Esse conflito se configura pela pressão dos órgãos, na 
qual privilegia a quantidade em detrimento da qualidade, provocando lacunas na formação didáticapedagógica do docente que atua na graduação (Vosgerau, Orlando \& Meyer, 2017; Silva \& Mafra, 2014)

$\mathrm{Na}$ fala dos coordenadores, essa dicotomia entre o que o mercado quer e o que a instituição exige não deve existir, pois o que foi percebido, na visão deles, foi que os órgãos reguladores tornam-se fundamentais para promover a linearidade entre os cursos e a formação dos docentes.

Esse aspecto de linearidade promovido pelas pressões do MEC foi apresentado durante as entrevistas com os coordenadores como fator mais positivo relacionado às forças coercitivas reguladoras, tanto no que se refere ao processo de elaboração das matrizes do curso, como no processo de formação dos corpos docente e discente da instituição. Com esse enfoque, Ferro e Gonçalves (2007) reforçam que o MEC surge para determinar projetos de reformas e leis envolvendo mudanças no sistema de avaliação do ensino, visando à busca pela aproximação da universidade com o mercado, a partir da obediência às demandas do mercado.

O MEC tem uma série de normas que nós precisamos cumprir, e acaba que o nosso PPC precisa estar alinhado com o MEC [...] é interessante essa ligação porque a gente precisa de uma certa linearidade de conversa entre os cursos e o $\operatorname{MEC}[\ldots] .(\mathrm{C}-1)$.

Mas, apesar desse aspecto positivo, os coordenadores ressaltaram que as diretrizes promovem essa padronização dos cursos, mas por outro lado, elas possuem alguns aspectos burocráticos, que não acompanham as mudanças do mercado, sendo necessário certa flexibilização da instituição para adequar as demandas do MEC e do mercado.

A forma que o MEC interfere hoje, nos cursos de graduação, o papel que ele representa, eu acho que precisaria mudar muitas coisas, só que a gente não pode mudar o MEC. Então, na verdade, de fato, a gente precisa se adequar. Procurar se adequar na melhor forma, buscar flexibilidade onde a gente encontre brecha para isso, até mesmo para que a gente não engesse o curso, para que a gente não pare no tempo, porque sabemos que tem norma que o MEC adota, que são muito engessadas, que dificultam muitas coisas. (C-4).

Outros aspectos levantados na discussão do grupo focal envolviam a dupla missão do docente (ensinar e pesquisar) com a busca constante pelo desempenho baseado em produção científica. Apesar dos dois grupos destacarem o distanciamento quanto ao cumprimento desse papel, o fato interessante é que, para os docentes, essa dupla missão com a busca por produção científica revela ser algo difícil de ser alcançada, devido à sobrecarga de papéis e responsabilidades. Já para os coordenadores, nas entrevistas, essa exigência é questão de quebra de paradigma e adequação a um novo papel do docente na contemporaneidade.

[...] as universidades estão entrando numa linha muita de produção de artigo e pouca relação com o mercado. 0 mercado quer da estrutura das universidades uma resposta as suas necessidades de mão de obra, e a mão de obra que está indo para as empresas é inteiramente desfocada do que está acontecendo no seu dia a dia. (D-III).

Essa dupla missão do docente está relacionada as pressões que os órgãos reguladores federais exercem sobre as instituições. Estabelecendo normas que definem o papel da universidade diante do tripé, na qual envolve atividades do ensino, pesquisa e de extensão. Assim, as universidades se diferenciam das outras IES. Os docentes, no grupo focal, apresentaram a queixa restringindo as exigências ao ato de ensinar e pesquisar e não ao papel do docente nas atividades de extensão.

Esse tema é muito paradoxo. Esse paradoxo do MEC de exigir produtividade e produtividade virar publicação é caso sério, essa é uma crise no mundo da publicação, virou uma indústria, virou uma máfia, virou tudo, quando se cria corporações e no nosso caso específico, ali, na linha de frente, cria mais um paradoxo, você tem que está ao mesmo tempo em sala de aula, dando aula e fazendo pesquisa e produzindo e [...] (D-VI).

0 docente encontra-se dentro dessa dicotomia: produção acadêmica e o trabalho do professor. Esse paradoxo é afetado duplamente pelas normas regulamentadas, que determinam regras, afetando diretamente a profissão do docente. Assim sendo, o docente é caracterizado de duas formas: de um lado, como trabalhador de um sistema produtivo-industrial; por outro, o produto do seu trabalho, ou seja, produção de tecnologia e conhecimento científico.

Perante essa força, destaca-se que os docentes precisam atuar no complexo sistema no qual envolve diferentes tipos de pressões institucionais e regulamentadoras. 0 sistema Qualis/CAPES, exerce pressão no trabalho do docente, que exige uma atuação forte no aspecto de produção de pesquisa. Além disso, tendem a colocar o docente em isolamento, pois impedem que ele tenha qualquer outro tipo de relação com o mercado (Silva \& Mafra, 2014). Esse pensamento difere da percepção dos coordenadores, pois eles acreditam que o docente se encontra num momento de restruturação do papel, no qual 
precisam se reposicionar, em frente às diversas demandas oriundas do mercado e da instituição, diante do duplo papel de ensino e pesquisa, tendo ainda que conciliar com o trabalho externo.

Mas ainda precisamos fortalecer isso, principalmente na nossa área, porque um dos grandes desafios que temos hoje é equilibrar a pesquisa e a prática. 0 professor hoje, que ministra qualquer disciplina do curso, ele precisa ter vivência e experiência na área em que ele vai ministrar a disciplina. (C-4).

Em contrapartida, o que se percebe é que mesmo diante de todas as exigências e demandas repassadas pelos órgãos reguladores às instituições e aos docentes, o sistema de ensino sobrevive em constantes inseguranças e incertezas. Além disso, outros aspectos reforçam a instabilidade nas condições do trabalho do docente, na medida em que se percebe o aumento da carga horária dentro do regime de trabalho; a cobrança ao atribuir ao docente outras responsabilidades, não apenas pelo compartilhamento de conhecimento em sala de aula e pelo desenvolvimento de pesquisa, mas por inúmeras atividades burocráticas de apoio e, por fim, pela submissão a rigorosos sistemas de avaliação, em que mede a eficiência e a produtividade do professor de forma objetiva (Mancebo, Maués \& Chaves, 2006).

Essa insegurança é que faz com que a gente fique meio tenso [...] eu nunca tinha tido uma disciplina cortada, então, assim quando eu tive nesse semestre [...] gente, faltou perna e eu descobri ainda pelo sistema que foi ainda pior, eu cheguei para dar aula, a turma já tinha começado, de repente não estava, não existia. (D-VIII).

Além da pressão do principal órgão regulador da educação, referente ao MEC, os coordenadores abordaram também a existência de outros órgãos, como por exemplo, os conselhos regionais dos cursos e como ponto negativo ressaltou que as diretrizes são estáticas em frente ao dinamismo do mercado e que as instituições precisam se flexibilizar dentro das normas para poder atender tanto às demandas do MEC como às do mercado.

Hoje a gente tem os conselhos de administração. Esse é um outro órgão que exerce, inclusive eles tiveram com a gente para apresentar essa nova proposta e a gente tem caminhado muito com eles, por que também são órgãos sinalizadores muito importante, mas em termos de diretrizes voltadas para o ensino e aprendizagem é o MEC. (C-3).

As relações entre as unidades de registro identificadas na análise da força coercitiva do órgão regulador apesar de distintas entre os dois grupos estão na sua maioria associadas ou são parte integradas entre si. Apenas a unidade referente à dimensão de ensinar e pesquisar/ produção cientifica, que, mesmo tendo sido apresentada pelos dois grupos, se mostraram contraditórias entre os grupos, na medida em que os docentes revelam a dificuldade de atuação diante desses papéis, já os coordenadores reforçaram a viabilidade desses papéis, por meio de um novo posicionamento dos docentes na contemporaneidade.

O campo educacional é um ambiente que sofre interferências de vários outros campos institucionais e o mercado é um exemplo (Bandeira \& Cunha, 2003). Diante dessa força coercitiva do mercado, na qual envolve tanto as demandas do mercado externo, como as demandas do mercado educacional das IES privadas, os dois grupos de coleta envolvendo os professores e coordenadores levantaram os mesmos aspectos, permanecendo assim as mesmas unidades de registro para análise.

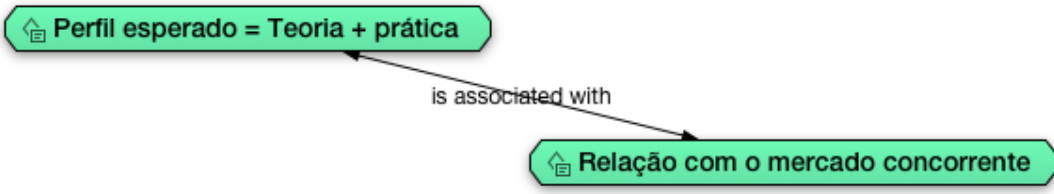

Figura 2. Resultados analisados no Atlas/TI: coleta de dados do Grupo Focal e Entrevista-categorias - mercado Fonte: Elaborada pelos autores com base nos dados da pesquisa (2016).

Como primeira análise, o aspecto abordado foi um mercado sendo consumidor do serviço ofertado pela instituição, a partir da oferta de alunos preparados para atuarem no ambiente externo, com conhecimento prático e teórico. E no segundo aspecto se refere ao ambiente educacional que se faz presente num mercado econômico em expansão, na qual se mostra competitivo e em constante busca pela qualidade.

Diante das demandas do mercado consumidor, os docentes e os coordenadores apontaram a 
importância da experiência prática como fator essencial para o exercício do ato de ensinar e na formação dos alunos. A relação entre teoria e prática se configura como fundamental para promover a revolução, na maneira como se ensina e como se aprende. 0 mercado anseia por profissionais práticos. 0 aprendizado deve ter fundamentação teórica, mas deve estar associado a ele uma vivência prática (Guimaraes \& Lima, 2016).

Nós vivemos no mercado e nunca deixei de ver o mercado e hoje nós temos aqui um escritório, com projetos abertos, abrindo projetos, ou seja, as empresas estão ficando tudo doida querendo vir atrás e falta gente, faltam colegas para escrever, escrever artigos e não é cientifico não, escrever coisa prática. (D-III).

O que o mercado anseia do nosso aluno [...] um profissional apto a participar de uma gestão efetiva de negócios, um profissional humanístico com uma dose de ciências humanas, forte no processo. Outro ponto atento à tecnologia, atento à mudança da legislação, ... então olha o leque de qualificação e de demanda e exigência do mercado sobre o aluno da instituição. (C-2).

Além do mercado consumidor, as IES privadas precisam se relacionar entre si, pois existe um mercado educacional em expansão. Para os docentes, esse mercado é visto como mais uma opção de mercado de trabalho e ao mesmo tempo que se apresenta como oportunidade, ele mostra-se cheio de ameaças e incertezas (Rowe, Bastos \& Pinho, 2011). E para os coordenadores, cada instituição precisa buscar a diferenciação para a permanência no mercado que se mostra competitivo. Os coordenadores ressaltaram que a diferenciação se faz necessária, mas, hoje, a relação de parceria é mais importante do que o estabelecimento de barreiras para a permanência no negócio.

E posteriormente assumi uma disciplina em uma outra instituição. Depois dessa disciplina eu trabalhava durante o dia e a noite era professor. Depois viraram duas, três, cinco, seis... chegou o momento em que eu tive que decidir se realmente eu ia seguir a carreira acadêmica ou se eu ia continuar como executivo. (D-II).

[...] a gente quer desenvolver um bom trabalho de forma ética, respeitando os nossos concorrentes, chamando para participarem quando couber essa participação e construindo pontos de comunicação, no lugar de construir barreiras, por que comunicação é isso. A gente vem desenvolvendo, tentando desenvolver essa parceria. (C-1).

Com o novo padrão educacional, surgido após a reforma de 1968, novas estruturas aparecem no mercado educacional, transformando os alunos em clientes e os cursos em produtos. Diante dessa nova perspectiva, o docente tem o aluno como um termômetro do processo de ensino e aprendizagem, seja ele um aluno passivo ou ativo em sala de aula. Ante essa realidade, o docente passa a ser um prestador de serviço e passa a ter que lidar com diversos tipos de aluno. Quando se depara com um perfil de aluno passivo que, ao invés de buscar uma formação madura e reflexiva, visa apenas à aquisição de conhecimento fácil e alcance de título (Alcadipani, 2011), esse termômetro deve ser equalizado, pois apresenta-se cheio de interesses pessoais.

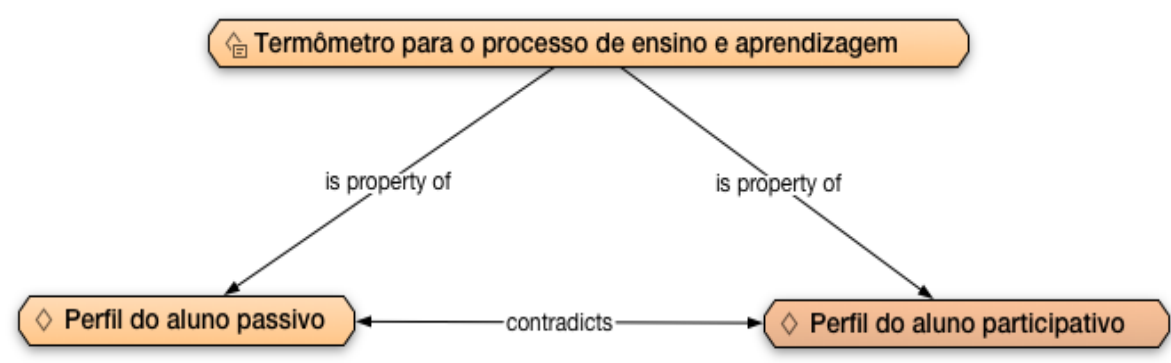

Figura 3. Resultados analisados no Atlas/TI: coleta de dados do Grupo Focal e Entrevistas - categorias cliente

Fonte: Elaborada pelos autores com base nos dados da pesquisa (2016).

O estudante universitário é um paradoxo ambulante, porque ele compra um produto que ele não quer. Ele está ali pagando por um negócio, entra na instituição e se não gostar sai. De uma turma de 55, vai ter uns 40 que não querem nada, vai ter uns 10 que se salvem quem puder e vai ter aqueles 5 que você sabe que são para esses que você vai está falando, mas de fato, você tem que conseguir ser bem avaliado por todos. (D-VI). 
Na discussão do grupo focal, não ficou evidente na fala dos docentes o outro perfil de aluno que se mostra exigente com a qualidade de ensino e do curso, em face do alto grau de competitividade de mercado de trabalho, conforme os estudos de Pachane e Pereira (2004), Zago (2006) e Setton (2005). Como também o perfil de diversidade cultural, diante do processo de internacionalização e do perfil de aluno com habilidades tecnológicas que surge na era digital, com uma postura mais curiosa e com grande habilidade na utilização de recursos tecnológicos conforme Freire Filho e Lemos (2008).

Enquanto os docentes percebem esse perfil de aluno como minoria em sala de aula, os coordenadores apontaram que a presença desse tipo de aluno na contemporaneidade tende a ser tendência natural perante o mundo competitivo e que exerce uma influência no trabalho docente, pois atua como termômetro avaliativo no processo de ensino e aprendizagem.

[...] percepção do aluno hoje, que é de fato a instituição tem é inegável, do aluno como cliente, mas não um cliente que sempre vai ter razão, em detrimento do professor, mas essa ideia de construção colaborativa [...] estão os nossos alunos, eles têm muita consciência de que eles estão pagando, que existe um serviço a ser prestado e que eles exigem uma qualidade desse serviço. (C-1).

Diante dessas forças, as influências geram reações diversas no docente, provocando em alguns, momentos percepções de conflito e em outros momentos de integração entre as forças. Tanto os docentes como os coordenadores trouxeram esse duplo sentimento, mas na fala dos envolvidos na pesquisa o aspecto de promoção de desenvolvimento profissional, por meio da busca por uma formação continuada, foi comum, na medida em que essas influências impulsionam o docente a sair da zona de conforto, provocando neles uma busca constante por reciclagem e atualização, em frente às mudanças da contemporaneidade.

Diante dessas pressões, o docente está tendo que enfrentar uma realidade que exige constante desenvolvimento, pois esse novo cenário de mudanças constantes no ambiente institucional na qual envolve a instituição, o mercado e o aluno demandam cada vez mais do professor uma postura diferenciada, a partir do desenvolvimento de novas estratégias que o permitam, pensar sobre sua missão como docente.

[...] o grande desafio do docente, primeiro, é a formação continuada com forte ênfase. Hoje vivemos no mundo de grandes mudanças, de grandes evoluções e os professores mais do que nunca devem trabalhar com atualização, tem que ter um perfil de visão de mercado muito bom. (C-2).

Outro aspecto percebido na fala dos participantes, relacionado a crescimento profissional, é que apesar das reformas educacionais estabelecerem um padrão entre titulação e carreira, o que se percebe na fala é que a busca por crescimento é muito mais por uma pressão pessoal e por uma iniciativa própria, do que pela cobrança da instituição, ou seja, outras alternativas são criadas para possibilitar o crescimento do professor (Balbacheshky, 2007). Apesar dessa percepção dos coordenadores, de reconhecer que as pressões dos órgãos impulsionam os docentes a serem mais competitivos no seu trabalho, acreditamos que a responsabilidade em desenvolvimento da carreira, deve ser algo compartilhado entre a instituição e o próprio docente, pois apesar da busca pela auto-gestão de carreira, a instituição precisa criar ambiente e promover momentos de formação do docente, pois essas ações refletem diretamente no serviço ofertado e, consequentemente, no desenvolvimento da própria instituição.

\section{Conclusões}

A pesquisa visou identificar as percepções dos docentes e dos coordenadores de cursos, sobre as forças coercitivas, por meio desse objetivo, percebeu-se que os docentes reconhecem as influências e atribuem a elas forças que atuam diretamente na rotina do professor, promovendo sentimentos negativos de angústias e incertezas quanto ao papel do docente em frente às demandas que surgem na contemporaneidade, refletida no mercado, no cliente, e nas instituições reguladoras. Quando analisado os dados dos coordenadores de cursos, as percepções sobre as influências das forças coercitivas revelam aspectos positivos capazes de promover linearidade de cursos e desenvolvimento do perfil dos docentes e discentes.

Pode-se constatar que as forças vindas dos órgãos reguladores apresentaram maior diferenciação de entendimento entre os 2 (dois) grupos estudados (docentes e coordenadores), tendo assim registros diferentes entre si durante a análise de conteúdo realizada. Os docentes trouxeram para discussão o duplo papel referente ao ato de ensinar e pesquisar, e o conflito entre os mundos academicista e 
mercadológico, que se encontram inseridos no ambiente institucional. Nessa discussão, fica evidente a problemática vivida pelos docentes sobre as novas exigências do papel do professor na contemporaneidade, envolvido dentro de um ambiente de ensino e pesquisa ao mesmo tempo. Entender essa lógica de produção das entidades que regulamentam, possibilita um outro estudo, pois as medidas adotadas exigem um papel com várias responsabilidades e atribuições.

Assim, conclui-se que o trabalho do docente se constitui ante as várias influências vivenciadas dentro do contexto educacional e social de mudanças. Nesse cenário de transição, o docente assume um modelo de gestão mais aproximado ao formato empresarial, no qual envolve a ocupação de múltiplos papéis e gestão com base em indicadores de resultados. E diante dessa perspectiva, os docentes apresentaram também a falta de prioridade do governo, presente a partir da carência de incentivo aos estudos e pesquisas, gerando incertezas e inseguranças no ambiente educacional.

Para os coordenadores, além da influência do principal órgão regulador da educação (MEC), outros órgãos federais, estaduais e municipais, como os conselhos dos cursos, foram evidenciados como forças impulsionadoras de promoção de desenvolvimento dos docentes e dos cursos por meio das diretrizes estabelecidas. O único aspecto negativo relatado foi que as normas estabelecidas não costumam acompanhar as mudanças do cenário externo e, na maioria das vezes, as instituições tendem a se adequar às normas, flexibilizando-se para não deixar de atender às demandas do mercado e do MEC.

Quando analisadas as forças coercitivas do mercado, os aspectos apresentados pelos dois grupos de coleta foram comuns. 0 primeiro aspecto aborda o perfil de aluno que o mercado espera, no qual envolve, além do conhecimento, a vivência prática adquirida em experiências vivenciadas no ambiente acadêmico. 0 outro aspecto apresentado pelo mercado, diz respeito à relação da instituição e do próprio docente com as outras instituições educacionais, que se mostram como concorrentes. Os docentes afirmaram a importância da busca pela diferenciação e reconheceram as outras instituições como oportunidades de atuação, refletindo bem o momento de expansão entre as IES. Já os coordenadores ressaltaram a diferenciação como fator importante, mas trouxeram também que se faz necessário o estabelecimento de elos de aproximação entre as IES, para garantir a permanência do negócio, por meio da criação de vínculos de boas parcerias com outras instituições.

Caracterizando a terceira força, que se refere aos alunos, pôde-se observar entendimento diferentes sobre o perfil do novo aluno. Enquanto os docentes relataram que, na maioria das turmas, os alunos se mostram passivos e pouco interessados em construir conhecimento; os coordenadores apresentaram que o novo aluno se mostra mais participativo e questionador. E na segunda percepção, o aluno se insere dentro de uma era de avanços tecnológicos, na qual se apresenta como curioso e com grande habilidade em utilizar recursos tecnológicos para as mais diversas finalidades, envolvendo desde de entretenimento até a consolidação de redes de sociabilidade. Mesmo com essa diferenciação de perfil, os dois grupos participantes da pesquisa destacam que os alunos são reconhecidos como peça fundamental dentro do processo de ensino e aprendizagem e servem como termômetro de avaliação, tanto para a instituição como para o docente.

E por fim, pode-se concluir, a partir da fala dos participantes, que a reação deles diante de todas as forças, de alguma forma, impulsionam os docentes a buscarem um desenvolvimento constante e a saírem da zona de conforto. Além disso, o que é percebido, dentro do ambiente educacional, é que as forças coercitivas exercem pressões externas e internas ao campo institucional e acabam influenciando o comportamento dos atores envolvidos; no caso estudado, os docentes. Por meio do estudo, novas possibilidades surgem de atuação do docente frente aos desafios que emergem. Diante das influências das forças, surge a necessidade de adequação de práticas metodológicas, para melhor atender às demandas do processo de ensino e aprendizagem. Para os coordenadores, a compreensão do cenário atual, do ambiente educacional superior, permite uma melhor gestão da equipe, na medida em que exige uma antecipação ao atendimento das expectativas, envolvendo tanto os docentes, como os alunos.

Assim, a teoria institucional permite explicar como as organizações se adaptam a sua estrutura e cultura, para enfrentar valores socialmente estabelecidos pelo ambiente externo e interno, tendo seu foco voltado para a institucionalização dos controles normativos, como padrões de crenças, valores e normas. Dentre as limitações deste estudo, recomenda-se, neste caso, que a pesquisa seja estendida para outros centros de estudo e em outras instituições, com outros campos de atuação, envolvendo também a pós-graduação. Dessa forma, seria possível a realização de uma análise comparativa entre os diversos centros, instituições e campo de atuações, enfatizando a identificação das características das forças coercitivas sobre o trabalho docente e a reação a cerca delas, por meio do olhar dos docentes e 
coordenadores de cursos. Além disso, pode ser analisado o olhar dos coordenadores, como uma outra força coercitiva, bem como, o olhar de outros "stakeholders", promovendo uma maior abrangência, por meio das percepções dos alunos, dos pais e da comunidade, permitindo uma análise compreensiva e comparativa dos consensos e dos dissensos, possibilitando uma maior exploração dos interesses e dominação dos agentes envolvidos.

\section{Referências}

Alcadipani, R. (2011, abril/junho). Academia e a fábrica de sardinhas. O\&S, Salvador, 18(57), 345-348. Alperstedt, G. D., Martignago, G., \& Fiates, G. G. S. (2006, janeiro/junho). 0 processo de Adaptação estratégica de uma instituição de ensino Superior sob a ótica da teoria institucional. Revista de Ciências da Administração, 8(15).

Balbachevky, E. (2017, janeiro/junho). Carreira e contexto institucional no sistema de ensino superior brasileiro. Sociologias, Porto Alegre, 9(17), 158-188.

Barbou, R. (2009). Grupos Focais. Porto Alegre: Artmed.

Bardin, L. (2012). Análise de Conteúdo. São Paulo: Edições 70.

Barreyro, G., \& Rothen, J. C. (2007, março). Avaliação e Regulação da Educação Superior: Normativas e Órgãos Reguladores nos 10 anos pós LDB. Avaliação, Campinas, 12, 133-144.

Bauer, M. W., \& Gaskell, G. (2002). Pesquisa qualitativa com texto, imagem e som (Pedrinho A. Guareschi, Trad.). Petrópolis: Vozes.

Bourdieu, P. (2011). Escritos de educação. São Paulo. Vozes. (Coleção Ciências da Educação). Brasil. (2011). Sinopses estatísticas do Censo da Educação Superior: 1995 a 2011. Brasília: MEC. Retirado de http://www.inep.gov.br/superior/censosuperior/ sinopse/default.asp Carvalho, C. A. P.; Vieira, M. M. F.; Lopes, F. D. Contribuições da perspectiva institucional para análise das organizações. Local: Editora, 1999.

Carvalho, C. A., Vieira, M. F. V., \& Silva, S. M. G. (2012, dezembro). A Trajetória Conservatória e Conservadora da Teoria Institucional. Gestão.Org, 10, 469-496.

Dimaggio, P., \& Powell, W. (1991). The new institutionalism in organizational analysis. Chicago: The University of Chicago Pres..

Ferro, R., \& Gonçalves, S. (2010, outubro). A Ambiente Organizacional e institucional: A emergência do Mercado do Ensino Superior Brasileiro no período de 1970 a 2007. Perspec. Contemp., Campo Mourão, 85-120.

Fraser, M., \& Gondim, S. M. (2004). Da fala do outro ao texto negociado: discussões sobre a entrevista na pesquisa qualitativa. Paidéia, 14(28), 139-152.

Freire Filho, J. F., \& Lemos, J. F. (2008, julho). Imperativos de conduta juvenil no século XXI: a “Geração Digital" na mídia brasileira comunicação. Mídia e Consumo, São Paulo, 5(13), 11-25.

Godoy, A. S. (2005, maio/agosto). Refletindo sobre critérios de qualidade na pesquisa qualitativa. Revista Gestão.Org, 3(2), 85-94.

Guimarães, J. C., \& Lima, M. A. M. (2016, abril/junho). Empreendedorismo Educacional: Reflexões para um ensino docente diferenciado. RPCA, Rio de Janeiro, 10(2), 34-49.

Hasselbladh, H., \& Kallinikos, J. (2000). The project of rationalizatiosn: a critique and reappraisal of neo-institucionalism in organization studies. Organization Studies, 21(4), 697-720.

Mancebo, D., Mauës, O., \& Chaves, L. J. (2006). Crise e reforma do Estado e da universidade brasileira: Implicações para o trabalho docente. Educar em Revista, Curitiba: UFPR, (28), 37-53.

Maués, O. (2009). Regulação educacional, formação e trabalho docente. Estudos em Avaliação

\section{Educacional.}

Meyer, J. W., \& Rowan, B. (1991). Institutionalized Organizations: Formal structure as Myth and Ceremony. In W. W. Owel, \& P. Dimaggio (Eds.). The New Institutionalism in Organizational Analysis. Chicago: The University of Chicago Press.

Minayo, M. C. de S. (Org.). (2001). Pesquisa Social. Teoria, método e criatividade (18a ed.). Petrópolis: Vozes.

Pachane, G. G., \& Pereira, E. M. A. (2004). A importância da formação didático- pedagógica e a construção de um novo perfil para os docentes universitários. Revista Iberoamericana de Educación. Rowe, D. E., Bastos, A. V. B., \& Pinho, A. P. M. (2011, novembro/dezembro). Comprometimento e Entrincheiramento na Carreira: um Estudo de suas Influências no Esforço Instrucional do Docente do Ensino Superior. RAC, Curitiba, 15(6), 973-992. 
Scaglione, L. T.; Costa, M. N. (2011). Avaliação da Educação Superior e a Gestão Universitária: Padrões de Qualidade Definidos pelas Instituições de Ensino Superior, pelo MEC e pela Sociedade, Incluindo ENADE, IDD, CPC e IGC. Anais do Colóquio Internacional sobre Gestão Universitária na América do Sul, Florianopolis, Brasil, 11.

Setton, M. Da G. J. (2005, janeiro/abril). Um novo capital cultural: pré-dispôs- ações e disposições à cultura informal nos segmentos com baixa escolaridade. Educação \& Sociedade, Campinas, 25(90), 77105.

Silva Jr., A., Silva, P., \& Mesquita, J. M. (2014). A dimensão teórica e metodológica do grupo focal no contexto da pesquisa qualitativa. In: E. Souza (Org.). Metodologias e Analíticas Qualitativas em Pesquisa Organizacional: Uma Abordagem Teórico-Conceitual - Dados Eletrônicos. Vitória: EDUSC.

Silva, I. C, \& Mafra, F. L. N. (2014). Trabalho docente, trabalho decente ou trabalho doente? Reflexões sobre o trabalho de professores universitários na contemporaneidade. VII Encontros de estudos organizacionais da Anpad.

Vosgerau, D. S.'A. R.; Orlando, E. de A.; Meyer, P. (2017). Produtivismo acadêmico e suas repercussões no desenvolvimento profissional de professores universitários. Educ. Soc. [online], vol.38, n.138. Zago, N. (2006, maio/agosto). Do acesso à permanência no ensino superior: percursos de estudantes universitários de camadas populares. Revista Brasileira de Educação, São Paulo, 11(32), 226-237. 